\title{
Hashtag Burnout? A Control Experiment Investigating How Political Hashtags Shape Reactions to News Content
}

\author{
EUGENIA HA RIM RHO, University of California, Irvine, USA \\ MELISSA MAZMANIAN, University of California, Irvine, USA
}

\begin{abstract}
Both hashtag activists and news organizations assume that trending political hashtags effectively capture the nowness of social issues that people care about [20]. In fact, news organizations with growing social media presence increasingly capitalize the use of political hashtags in article headlines and social media news post a practice aimed to generate new readership through lightweight news consumption of content by linking a particular story to a broader topic [28]. However, response to political hashtags can be complicated as demonstrated with the events surrounding \#MeToo and \#BlackLivesMatter. In fact, the semantic simplicity of political hashtags often belies the complexities around the question of who gets to participate [71], what intersectional identities are included or excluded from the hashtag [45], as well as how the meaning of the hashtag expands and drifts [10] depending on the context through which it is expressed. Overtime, reports show increasing backlash $[70,73,74]$ and polarization $[21,52,66,67,70]$ against key issues embodied by political hashtags. In this vein, we assume that political hashtags affect how people make sense of and engage with media content. However, we do not know how the presence of political hashtags -signaling that a news story is related to a current social issue - influences the assumptions potential readers make about the social content of an article. In this work we conducted a randomized control experiment to examine how the presence of political hashtags (particularly the most prevalently used \#MeToo and \#BlackLivesMatter) in social media news posts shape reactions across a general audience $(n=1979)$. Our findings show that compared to the control group, people shown news posts with political hashtags perceive the news topic as less socially important and are less motivated to know more about social issues related to the post. People also find the news more partisan and controversial when hashtags are included. In fact, negative perception associated with political hashtags (partisan bias \& topic controversy) mediates people's motivation to further engage with the news content). High-intensity Facebook users and politically moderate participants perceive news with political hashtags as more partisan compared to posts excluding hashtags. There are also significant differences in discourse patterns between the hashtag and control groups around how politically moderate respondents engage with the news content in their comments.
\end{abstract}

CCS Concepts: • Human-centered computing $\rightarrow$ Collaborative and social computing $\rightarrow$ Empirical studies in collaborative and social computing

\section{KEYWORDS}

political hashtags; political discourse; civil discourse; democracy; polarization; online social movements; SNS; social media news consumption; digital journalism; path analysis; control experiment; survey design

\section{ACM Reference format:}

Eugenia Ha Rim Rho (hrrho@uci.edu), Melissa Mazmanian (m.mazmanian@uci.edu). 2019. Hashtag Burnout? A Control Experiment Investigating How Political Hashtags Shape Reactions to News Content. In Proceedings of the ACM on Human-Computer Interaction, Vol. 3, CSCW, Article 197 (November 2019), 25 pages, https://doi.org/10.1145/3359299

\footnotetext{
Permission to make digital or hard copies of all or part of this work for personal or classroom use is granted without fee provided that copies are not made or distributed for profit or commercial advantage and that copies bear this notice and the full citation on the first page. Copyrights for components of this work owned by others than ACM must be honored.

Abstracting with credit is permitted. To copy otherwise, or republish, to post on servers or to redistribute to lists, requires prior specific permission and/or a fee. Request permissions from Permissions@acm.org.

2573-0142/2019/November-ART196 \$15.00

Copyright is held by the owner/author(s). Publication rights licensed to ACM.

. https://doi.org/10.1145/3359299
} 


\section{INTRODUCTION}

\subsection{Employment of Political Hashtags by News Organizations}

From the earliest work on political hashtags in the context of the Arab Spring $[12,29,63]$ to the more recent studies based on the \#MeToo [44, 56] and \#BlackLivesMatter movements [33, 64, 71], researchers have shown how hashtag activism or "hashtivism" [54] has succeeded in stimulating critical conversations around contested political and social topics [15, 22, 48, 54, 71]. However, several years after gaining attention in popular media and scholarly research [62], it remains unclear how political hashtags affect awareness and participation around social and political issues $[45,68,70,73]$. How do political hashtags frame how people make sense of and engage with media tagged in a certain way? Are political hashtags truly fostering constructive civil discourse and raising positive awareness around key social issues as demonstrated by prior literature $[15,39$, $40,48,54,71]$ ?

Specifically, in the news context, political hashtags or those related to social issues signal that a tweet or a Facebook post (and by extension the linked article) is related to a particular trending social issue or topic [28]. In that sense, news organizations increasingly competing for audience attention on social media news feeds, often use trending hashtags to increase readership [20,28] or to contextualize their article in short, digestible posts. According to a recent Pew Research study on major news organization practices, "the lack of hashtag usage [would be] surprising as hashtags would enhance the chance that a news organization's stories will be read by individuals who are not already following their feed" [28]. In a similar note, according to Columbia Journalism Review, not only is "hashtag activism [a] good way to introduce a story or perspective into the mainstream news cycle", but also "a way to figure out what the public wants to discuss and learn more about" [20]. This creates an "added bonus that when journalists add more reporting and perspective to the conversation, their work gets duly hashtagged and receives an added boost" [20]. Thus, it is not surprising that major news outlets are crafting headlines and social media news posts to include hashtags, some of which are often political or explicitly related to social issues [28]. For this tactic to be effective, it is common for news writers to capitalize on political hashtags that are known to have "gone viral" and thus have broad resonance with the current and potential readership [20].

News articles on social media (hereby, referred to as news posts) are important spaces for online civil discourse around social issues $[50,55]$. Ideally, the inclusion of these political hashtags in articles headlines and news posts should foster heated, but constructive debate that generates a diversity of perspectives through discussion and greater interest in social issues. However, discourse surrounding political hashtags are often complicated [40,62]. The virality of a political hashtag may denote the magnitude of people's interest in the social issues embodied by the hashtag, and perhaps willingness to engage and know more about the issue [20, 28]. However, at the same time, as with most political content that goes viral, political hashtags in social media news articles may also potentially frame the article with the political baggage (e.g., partisan bias $[52,71]$ and controversy $[50,64]$ associated with the hashtag.

\subsection{Motivation of Research}

The goal of our work is to examine the how political hashtags in social media news posts focusing on social issues affect people's reactions toward the social topic of the news content. Through a randomized control experiment, we examine how the presence vs. absence of political hashtags (particularly the most prevalently used \#MeToo and \#BlackLivesMatter) in social media news posts (articles shared on Facebook by news publishers) shape reactions across a general audience $(n=1979)$. We launched a survey randomizing the display of news posts to participants who answered questions and commented in reaction to the news post that either contained or excluded the political hashtag (control group) as shown in Figures 1A and 1B. 
We specifically chose \#MeToo and \#BlackLivesMatter for this experiment based on two key criteria. First, we chose political hashtags that were directly related to broad social issues (e.g., not tied to a particular individual or a political campaign slogan). This criterion was implemented, because our study was designed to understand the impact of hashtags that frame pressing social issues on people's experience of news consumption.

Second, our selection focused on political hashtags that were published in the headlines of actual news stories put out by major news outlets at least five times in the past up until the time of survey design (December 2018). Criterion two was implemented, because this study examined hashtags that were being regularly used to frame news stories in major outlets, thereby suggesting broad resonance of the hashtag. Further, the fact that mainstream news sources were employing particular hashtags in the headlines suggests that they were deemed not overly-inflammatory. Only two hashtags fit within these criteria and thus were used in the experimental manipulations of this study.

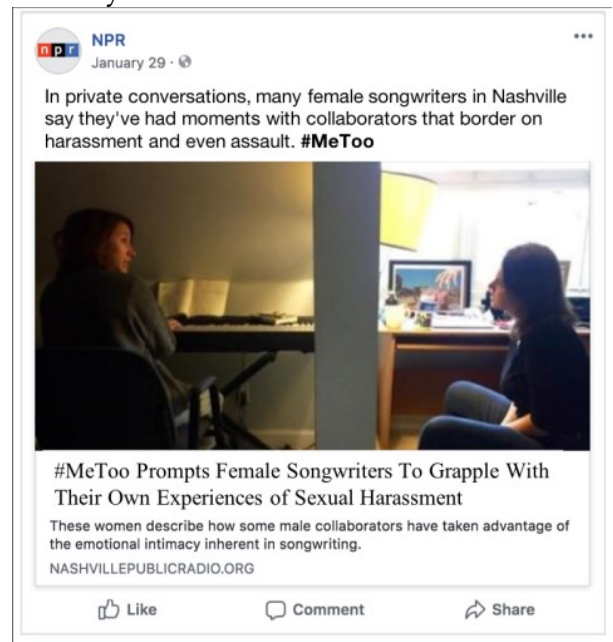

Fig 1A. News post with \# (hashtag group)

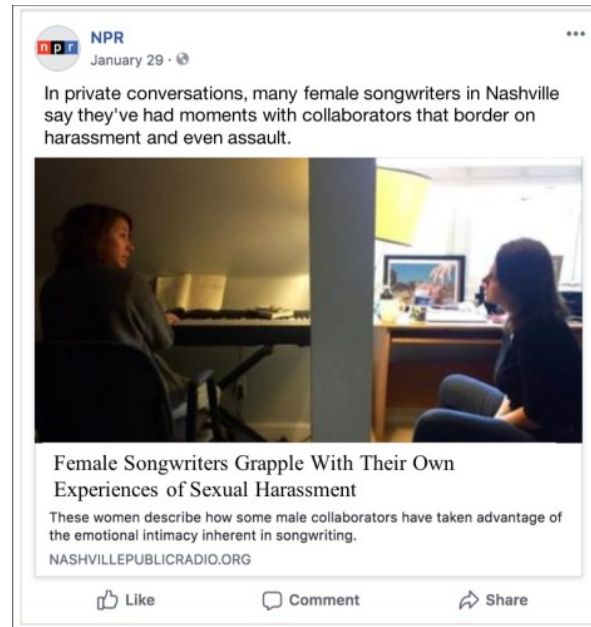

Fig 1B. News post without \# (control group)

Fig. 1. The original news post (Figure A, Appendix) was identical to the hashtag condition on the left, except for the bolded \#MeToo followed by the text description. For the control condition (right), we excluded the hashtag in the post text, as well as the phrase "\#MeToo Prompts" in the headline.

The purpose of our work is to investigate whether political hashtags motivate or deter people from wanting to further engage with related social issues and by large, their impact on civil discourse in online venues through news posts on social media. Key findings from our work show that:

1. Compared to the control group, participants who were shown news posts with political hashtags:

- H1a: perceived the news topic to be significantly less socially important

- H1b: were significantly less motivated to know more about social issues related to the news post

- H2a: found the news post to be significantly more partisan

- H2b: found the topic of the news post to be significantly more controversial

2. Negative perception (pertaining to perception of partisan bias \& topic controversy) mediates the impact of political hashtags on motivation for reader engagement (perception of social importance of news topic and motivation to know more about social issues related to the news post). 
3. Compared to news posts without political hashtags, news with hashtags were perceived significantly more partisan among those who use Facebook more often as well as those who are politically moderate.

4. Among the politically moderate, there were key differences in discourse patterns between the hashtag and control groups in their commenting behavior on news posts.

\section{BACKGROUND}

\section{1 \#MeToo and \#BlackLivesMatter}

According to Twitter, \#BlackLivesMatter was the third most tweeted social-issue hashtag in the 10-year history of the platform [74]. From its first appearance in mid-2013 to March 2016, \#BlackLivesMatter was tweeted nearly 12 million times, frequently used in support of the broader social movement [74]. Similarly, within 24 hours of the first \#MeToo post in October 2017, the hashtag was tweeted more than 500,000 times and used by more than 4.7 million Facebook users in approximately 12 million posts [60]. Since then, the hashtag spread across 85 countries in multiple languages with the intent to share and bring attention to the pervasiveness of sexual harassment [51]. There is no doubt that political hashtags can be strategically leveraged for promoting social awareness as proven by \#MeToo and \#BlackLivesMatter [22, 44, 56, 71, 74]. These online social movements effectively demonstrated a political hashtag's ability to rapidly scale across online platforms, enabling people to aggregate discussion [71] and heighten visibility on police brutality and sexual harassment issues [56, 62].

However, one year after the \#MeToo movement, reports now show that people's opinions have shifted against \#MeToo survivors. According to polls, people are more and more divided on issues surrounding sexual harassment - with the divide running primarily along partisan groups [73]. Similarly, several years after the Black Lives Matter came to national prominence the majority of Americans now have an unfavorable view of the movement [53], again cutting sharply on racial and partisan lines [49].

\subsection{Literature on Hashtags as Related to Social Issues}

Research exploring political hashtags in the context of democratic discourse highlights how hashtags promote public awareness around social issues through personalized storytelling [48] and expression of solidarity[15, 15, 43]. Findings from Computer-Supported Cooperative Work (CSCW) and Human-Computer Interaction (HCI) literature have generally focused on how political or social-issue hashtags act as resources for particular communities to coalesce around shared interests $[1,5,11,17,36,62,64]$ and assert particular identities [13, 32, 43, 57]. In this vein, scholars have explored how hashtags inform debate around political issues [26] and challenge public perceptions around contested social topics $[8,14,36]$. This scholarship generally takes the perspective of the communities who are using hashtags to provide a frame for social issues around which they already affiliate [1,27, 32, 34-36, 50]. Implicit in this work is the assumption that hashtagged media is received in manner aligned with the goals of the community using political hashtags to promote awareness of a particular issue [32, 40, 43, 57]. As such, political hashtags are seen as agentic frames that inspire new forms of democratic activism and social dialogue in the social media landscape $[15,39,40,54,56,71]$.

We see this perspective in the shift in how scholars discuss "slacktivists" $[39,63]$. Once pejoratively defined as "those who sit on a comfortable couch in their living room watching TV or interacting with others solely on social media" [54], the term "slacktivists" is used in recent studies with less derision- for example, as someone whose "vicarious participation has a more meaningful and new connection to the hard work of the social movement than is readily visible" [63]. This vicarious participation, namely, "reading, retweeting, commenting on others' tweets or posting 
their own with the same hashtag" [71] is seen as having the power to curate narratives that "provoke empathy, foster polyvocality, and ultimately expand the engaged community" [48].

Such an assumed link between social-issue hashtags and political engagement is common in HCI research. Take statements such as: "Twitter is a democratic media, because it allows for [realtime] democratic activism" through hashtags [62] and "posting a political hashtag can be seen as a participatory act" [62]. Starbird et. al, state in no uncertain terms that "slacktivism may indeed have been a productive component of [a] revolution" [63]. Such forms of democratic participation may exist and be facilitated by political hashtags. However, these findings do not guarantee that political hashtags lead to interest in social issues or increased democratic engagement more broadly. Without an empirical examination of how political hashtags denoting current social issues are actually received by a general population, we cannot fully understand the role of political hashtags in demarking, motivating, and promoting democratic and social engagement.

\subsection{Overrepresentation of "Those Who Care" in the Data: Current Methods \& Practices in Data Collection \& Analysis of Political Hashtags}

Prior research on political hashtags tends to focus on those who use hashtags in posting and tweeting media content rather than the less vested on-lookers who may only read and consume hashtagged content $[9,10,40,54,62]$. Given the common process of collecting data through APIfiltering of tweets or comments that include specific hashtags, this focus on hashtag creators is an inevitable outcome of prevailing methods. However, these methods overrepresent those who have a specific opinion about the political hashtag or the social issues embodied by it while underrepresenting a large majority of those with a more neutral or moderate stance. Therefore, in statements such as, "I argue that a hashtag's narrative logic-its ability to produce and connect individual stories-fuels its political growth" [15], the term "political growth" is expressed with a positive connotation. The question remains, is that growth fueled by the already converted? Or are political hashtags providing energy and awareness to new audiences who were not already sympathetic to the issue at hand?

Furthermore, scholarship tends to focus on the emergence of a political hashtag and accompanying social awareness of the issues it represents - often the first weeks to months leading to a hashtag's viral peak. This can result in a data that represents the initial intense and heated conversations from the point in time when the hashtag was "most-tweeted" or "trending" [26, 44, 56, 71]. Such scholarship cannot avoid oversampling people who are emotionally-vested (via tweets and posts) and "tuned-in" to an issue. We know little about what happens over time and whether political hashtags that are no longer trending play a different role in democratic participation.

Both qualitative and quantitative work based on such samples draw conclusions about the productive power of hashtags for social movements [10, 43, 63]. Such work finds, for example, that "hashtag activism is effective... in ensuring social movements remain within the public discourse through the use of viral Twitter hashtags" [61]. Whether or not such findings are the effect of the timing and methods for data collection has yet to be examined.

\subsection{Computational Approaches to Understanding Social Engagement Through Political Hashtags}

Computational research on social media hashtags often use the frequency of tweets as proxies for understanding social engagement around political hashtags $[10,26,40,58]$. In an effort to understand what makes a hashtag "successful" Lin et al. quantify "conversational vibrancy" [40] surrounding hashtags through multiple measures of volume. The authors define the measure of topicality based on "the number of times a hashtag is retweeted" [40], diversity as "the number of unique tweets with the hashtag" [40], and interactivity based on "the number of replies cooccurring with the hashtag" [40]. 
Similarly, in an attempt to understand "what makes a hashtag "successful" or "[spread] like a best-selling book" Romero et. al quantify social engagement through "stickiness" or the probability of a tweet with a hashtag spreading from one person to another. Their findings demonstrate that political hashtags are more persistent compared to non-political ones [58]. Studies examining the relationship between hashtags and democratic participation cite these computational findings as evidence that political hashtags get stronger and more powerful from repeated exposures ([10] citing [58]). However, we do not know whether escalation in volume of hashtagged content is snowballing within specific groups (the volleying of content within an information bubble) or reflecting positive impact on a more general audience.

Furthermore, studies on political hashtags that involve large longitudinal network datasets can run the risk of collapsing the data into a single snapshot [33] when employing quantitative approaches that solely rely on volume-based metric for engagement. Aggregating and quantifying most frequent tweets and posts from a single longitudinal data dump can leave out key temporal dynamics and contexts around how social engagement surrounding political hashtags evolve over time [33]. While findings from such computational approaches provide valuable high-level insights about network patterns $[10,30,38,59,72]$, these methods cannot address whether quantified definitions of a political hashtag's success hold true over time or across a broader audience.

\subsection{Development of Research Questions \& Hypotheses}

\subsubsection{RQ1: How Does the Presence of Political Hashtags in News Posts Affect Reaction Towards News}

Content Across a General Audience? We know that people who use political hashtags are doing so to denote alignment with an issue [40], personalize expression of why a particular story is important [43], and encourage others to engage in the content of the news story [55]. We do not know how this practice is received and whether or not a general audience engages with hashtagged news content in a manner that is aligned with this intent. As mentioned earlier, computational approaches to understanding the value of political hashtags have operationalized frequency and volume of tags as positive engagement and social interest around hashtagged content $[10,26,40,59]$. Yet again, these studies rely on data from hashtag producers rather than passive consumers. Therefore, we do not know for sure whether engagement and social interest around political hashtags translate between these groups. Through this research question we investigate whether political hashtags motivate or deter people from wanting to further engage with related social issues and by large, their impact on civil discourse in online venues through news posts on social media.

In order to understand whether the inclusion of political hashtags in news posts leads to motivation for constructive civil discourse and engagement as assumed by certain news practitioners and hashtag activists, we focused on two key aspects in participants' reaction to the news posts - motivation for engagement and negative perception.

Hypothesis 1: For motivation for engagement, we asked whether participants found the topic of the news post (referring to the randomized article post shown to the participant in the survey) was socially important (Social Importance of News Topic) and whether they wanted to know more about social issues related to the news post (Motivation to Know More). In Table 1, we show the corresponding questionnaire items in the survey that served as dependent variables to test our hypotheses. All survey items for the dependent variables were rated on a 5-point agreement Likert scale response.

Hypothesis 1 tests motivation for engagement towards news posts with vs. without political hashtags as follows.

- H1a: presence of political hashtags significantly influences perception of social importance towards the topic of the news post. 
- H1b: presence of political hashtags significantly influences willingness to know more about social issues related to the news post.

Table 1. Questionnaire items for the dependent variables.

\begin{tabular}{|c|c|c|}
\hline \multicolumn{2}{|c|}{ Dependent Variables } & Questionnaire Item \\
\hline \multirow{2}{*}{$\begin{array}{l}\text { Positive } \\
\text { Engagement }\end{array}$} & Social Importance of News Topic & $\begin{array}{l}\text { I find the topic of this news post to be } \\
\text { socially important. }\end{array}$ \\
\hline & Motivation to Know More & $\begin{array}{l}\text { I want to know more about social issues } \\
\text { related to this news post. }\end{array}$ \\
\hline \multirow{2}{*}{$\begin{array}{l}\text { Negative } \\
\text { Perception }\end{array}$} & Partisan Bias & $\begin{array}{l}\text { The partisan (liberal vs. conservative) } \\
\text { undertone of this news post is obvious. }\end{array}$ \\
\hline & Topic Controversy & $\begin{array}{l}\text { I find the topic of this news post to be } \\
\text { controversial. }\end{array}$ \\
\hline
\end{tabular}

Hypothesis 2: Although popular political hashtags are used by news publishers to denote an article's broader topical relevance to a social issue trending in discussion, we also know that people use popular hashtags to denote that they align with political and social identities $[9,40]$. We also see "hashtag wars" when political hashtags are used as a form of expressing commentary and backlash against the initial issue and movement [26, 34]. Therefore, political hashtags, especially in political outlets can be wielded as partisan tools that spur excessive controversy and division, thereby undermining conditions for civil discourse [55].

Through Hypothesis 2, we examine whether and how negative perceptions pertaining to partisanship and controversy associated with political hashtags shape reactions toward news content. Hence, we asked participants about their perception of partisan bias (Partisan Bias) of the randomized news posts they saw and whether they found the topic of news post to be controversial (Topic Controversy).

Hypothesis 2 tests how political hashtags shape negative perceptions towards news content.

- H2a: presence of political hashtags is significantly associated with perception of partisan bias towards the news post.

- H2b: presence of political hashtags is significantly associated with whether people find the topic of the news post to be controversial.

2.5.2 RQ2: How Do People Across the Political Spectrum, Particularly the Politically Moderate, Respond to News Posts Framed with Political Hashtags? \#MeToo and \#BlackLivesMatter are regarded as hashtags denoting "liberal" issues $[15,32,48,57]$. Prior research suggests that people who already have strong feelings about an issue or are polarized to the right and left of the political spectrum, employ political hashtags in attempt to control discourse [6,12]. As mentioned earlier, by focusing on this population - people using rather than consuming hashtags - research may be inflating the impact of political hashtags to enhance mobilization around social issues. We can assume that those on the left and right have strong feelings about the presence of political hashtags in news content. However, we do not know how more moderate people engage with social issues online. Through this question we investigate how people who identify as politically 
moderate 1 respond to news posts that either include or exclude a well-known political hashtag, such as \#MeToo and \#BlackLivesMatter.

2.5.3 RQ3: How Does the Presence of Political Hashtags Affect Perception of Partisan Bias Towards News Post Across High vs. Low Intensity Facebook Users? Prior work has shown that increased exposure to opposing political views on social media can increase political polarization [2]. Through this research question, we investigate whether repeated exposures to political hashtags may influence perception of partisan biases as well. Assuming those who use Facebook more frequently are likely to have a higher chance of being exposed to these social media hashtags, we compared responses around perception of partisan bias between two different levels of Facebook use - high (use Facebook several times per day) and low (less than once per week) intensity users.

\section{METHOD \& EXPERIMENT DESIGN}

\subsection{Experimental Setup}

To understand how the presence of political hashtags influences people's perception of news posts, we conducted a $2 \times 3$ factorial experiment with the following factors and levels:

Political Hashtag: (1) included, (2) excluded in the news post

Comments: (1) no comment, (2) positive comment, (3) negative comment

We included positive and negative comments as a second factor to mirror closeness to reality of the news posts in the social media 'wild' as they often contain affective comments under the article comment threads [18, 25, 37]. Prior work has shown that negative comments induce more negative reactions towards social media news posts [25]. Hence, we included affective comments in our experiment to control for reactions towards hashtagged vs. hashtag-absent news content.

Table 2. 2x3 Factorial design with hashtags \& affective comments as manipulated factors. A total of 48 news posts ( 2 political hashtags $\times 4$ news posts $\times 6$ scenarios) were randomly displayed in the survey.

\begin{tabular}{|c|c|c|}
\hline & Hashtag & No Hashtag \\
\hline $\begin{array}{l}\text { No } \\
\text { comments }\end{array}$ & $\begin{array}{l}\text { Scenario 1: Article headline \& the text } \\
\text { portion of the news post include the } \\
\text { hashtag while preserving the intended } \\
\text { message of the content as much as possible. }\end{array}$ & $\begin{array}{l}\text { Scenario 2: Article headline \& the text } \\
\text { portion of the post exclude the hashtag } \\
\text { while preserving the intended message of } \\
\text { the content as much as possible. }\end{array}$ \\
\hline $\begin{array}{l}\text { Positive } \\
\text { comments }\end{array}$ & $\begin{array}{l}\text { Scenario 3: Supplemented scenario } 1 \text { with } \\
(+) \text { comment below the post. }\end{array}$ & $\begin{array}{l}\text { Scenario 4: Supplemented scenario } 2 \text { with } \\
(+) \text { comment below the post. }\end{array}$ \\
\hline $\begin{array}{l}\text { Negative } \\
\text { comments }\end{array}$ & $\begin{array}{l}\text { Scenario 5: Supplemented scenario } 1 \text { with (- } \\
\text { ) comment below the post. }\end{array}$ & $\begin{array}{l}\text { Scenario 6: Supplemented scenario } 2 \text { with (- } \\
\text { ) comment below the post. }\end{array}$ \\
\hline
\end{tabular}

3.1.1 Selection of Hashtagged News Posts. For the experiment, we used a total of eight news posts - four news posts topically focused on \#MeToo and four on \#BlackLivesMatter from the New York Times (NYT) and NPR ${ }^{2}$. The authors reviewed all Facebook article posts published by NPR

\footnotetext{
${ }^{1}$ We use the 7-point Likert scale on Political View (1=Extremely Liberal, 2=Very Liberal, 3=Liberal, 4= Moderate or Middle of the Road, 5=Conservative, $6=$ Very Conservative, $7=$ Extremely Conservative) commonly employed by national survey institutions.

${ }^{2}$ NPR and NYT are considered left-center (relatively close to mainstream) according to mediabiasfactcheck.com. We discuss selection of news source in the limitations section.
} 
and NYT containing the hashtags as well as articles that appeared in the search results and were topically related to the hashtags. After reviewing each news post based on its headline and the text portion of the news post, we selected four articles per hashtag. Selection was primarily based on whether the intended message of the article could be best preserved with minimal modification of the headline and post text when including and excluding the hashtag.

We included several articles in this study to ensure that the effect of hashtags was not a product of how the hashtag was used in the headline or the content of the article. For example, when the hashtag \#BlackLivesMatter is included in an article on police killing versus an article about race in education, the emotional intensity in which the hashtag is framed is clearly different. Hence, including several articles in rotation reduced participant biases from overcontextualization.

3.1.2 Selection of Positive \& Negative Comments. We reviewed all the original comments from the eight news posts and separated positive and negative comments into two groups. We then selected comments that were clearly positive and negative as well as relevant to the article or the social topic of the news post. After screening out comments that failed to meet this initial criteria (e.g., expletives, emoticons, comments in foreign language, etc.), we then invited three researchers to our lab who were asked to rate the comments shown below each of the 48 scenarios ( 8 articles $\mathrm{x}$ 6 scenarios) in terms of three criteria: (1) clarity of language, (2) emotional intensity of language, and (3) positive vs. negative stance towards the issue of women's rights and protection from sexual harassment for \#MeToo posts and/ or black rights and racial equality for black people against police brutality for \#BlackLivesMatter posts ${ }^{3}$. The researchers then discussed interactively with the main authors throughout the rating process. For each of the 8 news posts, we finally selected one positive and one negative comment to be added below the post for scenarios 3 and 6 (as shown in Figures 2A and 2B). All personal information in these comments were de-identified to ensure the original commenter's privacy.

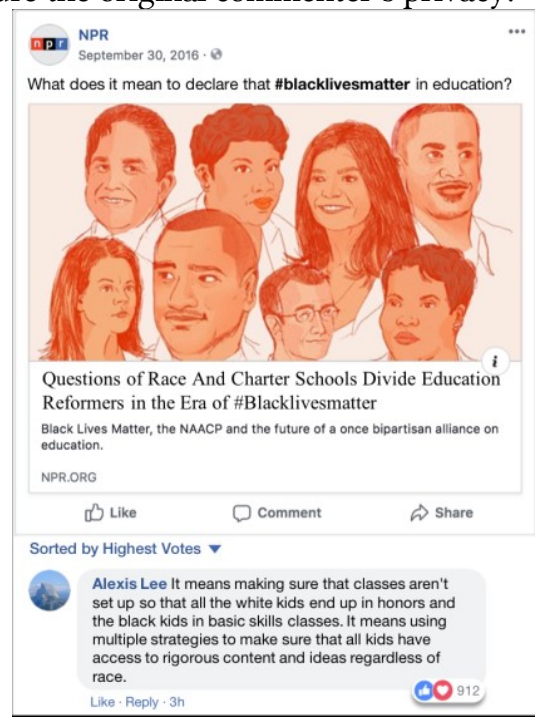

Fig 2A. Hashtag + Positive Comment

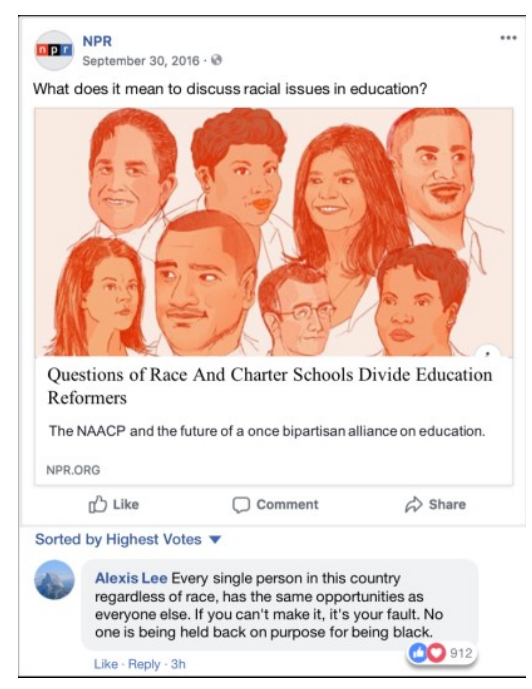

Fig 2B. No Hashtag + Negative Comment

\footnotetext{
${ }^{3}$ All ratings were based on a 5-point agreement Likert scale response to the following statements:

1. The language used in this comment is clear to understand.

2. The emotional intensity of the language used in this comment is moderate.

3. This comment is clearly positive towards women's rights and/ or protection from sexual harassment (or black rights and racial equality for black people).

Inter-rater reliability for the three criteria were relatively high $(0.92,0.90$, and, 0.98 , respectively.
} 


\subsection{Survey Deployment}

We used Qualtrics to design the survey, which randomly displayed one of the 48 scenarios to each participant. Participants were asked to answer questions about the news post in addition to leaving a comment in reaction to the news post. We launched the survey on Amazon Mechanical Turk across English-speaking workers over the age of 18 residing in the United States. Workers were compensated an hourly rate of $\$ 8-\$ 10$ for completing the assignment.

3.2.1 Participant Data. A total of 1979 participants (47\% female, mean age 36.5) completed the experiment, with an average of 330 participants for each scenario (Table 3 ).

Table 3. Participant sample breakdown in each scenario $(\mathrm{n}=1979)$

\begin{tabular}{ccc}
\hline & Hashtag & No Hashtag \\
\hline No comments & 340 & 323 \\
$(+)$ comments & 325 & 339 \\
(-) comments & 320 & 333 \\
\hline
\end{tabular}

More specific details on participant demographics are shown in Table A (Appendix). In aggregate, these workers contributed 1979 comments in reaction to the news post they saw in the survey (with an average of 24.8 words or 115 characters written per post).

\subsection{Analysis}

RQ1: To understand how presence vs. absence of political hashtags affect various perceptions related to motivation for engagement $(\mathrm{H} 1)$ and negative perception $(\mathrm{H} 2)$, we used regression models with Social Importance of News Topic, Motivation to Know More, Partisan Bias, and Topic Controversy as outcome variables.

Furthermore, for our regression models, we included gender, political view, and comment valence as control variables to eliminate potential confounding effects for the following reasons.

Gender: Research shows that women and men use different linguistic styles when tweeting political hashtags [16] and that women tend to use political hashtags less frequently [3, 75]. Given these findings, we included gender as a control variable to control for reactions towards hashtagged news posts in our experiment.

Comment Valence: As previously mentioned, affective comments are known to shape reactions towards online content; hence, we included comment valence as a control variable $(-1=$ negative comment, $0=$ no comment, $1=$ positive comment).

Political View: Given that people with varying political orientation interpret political hashtags differently [9], we asked respondents to report their political view based on a 7-point Likert scale (see footnote 2).

$R Q 2 \& R Q 3:$ To compare how presence vs. absence of political hashtags affect reaction among the politically moderate, we conducted a t-test between the control and the hashtag group across those who identified as politically moderate (Political View $=4$ ). We then conducted discourse analysis [23] on all the comments left by those who identified as politically moderate and present selected findings. For RQ3, we followed a similar procedure focusing on high-intensity Facebook users.

\section{RESULTS}

Our findings show that compared to the control group, those who were shown hashtags in their news posts perceived the news content as less socially important and were less motivated to know more about social issues related to the post. Furthermore, respondents found the news more 
partisan and controversial when hashtags were included. In fact, perception of partisan bias and topic controversy towards news posts is the mechanism through which people perceive hashtagged news posts to be less socially important and are less motivated to know more about related social issues. Further, compared to news posts without hashtags, news with hashtags were perceived significantly more partisan among those who use Facebook more often as well as those who are politically moderate. Between the hashtag and control groups, there were also significant differences in discourse patterns around how politically moderate respondents engaged with the news content in their comments.

\subsection{RQ1: Presence of Political Hashtags in News Posts Decreases Motivation for Engagement \& Increases Negative Perception}

4.1.1 H1a: People Perceive the News Topic to Be Significantly Less Socially Important When Hashtags Are Included in News Posts. Presence of political hashtags in news posts emerged as a significant negative predictor of motivation for engagement. Our regression output (Table 4) demonstrates that the presence of political hashtags in news posts negatively affects people's perception that the news topic is socially important (a .048 standard deviation decrease in perception of social importance of news topic). In other words, when political hashtags are included in news posts, people perceive the news topic to be significantly less socially important. Our control variables also significantly contribute to a decrease in perception of social importance, showing that men (compared to women) and those who are politically conservative (compared to those identified as politically liberal) find the news topic less socially important. Comment valence is also a significant predictor. Compared to those shown news posts with negative comments, participants who saw news posts with positive comments found the news topic to be significantly more socially important.

Table 4. Results of standardized linear regression model examining how the presence of political hashtags in news posts affect motivation for engagement towards the news post in terms of social importance of news topic $(\mathrm{H} 1 \mathrm{a})$ and motivation to know more about social issues related to the news post $(\mathrm{H} 1 \mathrm{~b})$.

\begin{tabular}{lcccccc}
\hline & \multicolumn{3}{c}{ DV= Social Importance of News Topic } & \multicolumn{3}{c}{ DV $\begin{array}{c}\text { Motivation to Know More about } \\
\text { Related Social Issues }\end{array}$} \\
\hline & B & SE B & $\beta$ & B & SE B & $\beta$ \\
Hashtag Present & $-0.100^{*}$ & 0.042 & $-0.048^{*}$ & $-0.137^{*}$ & 0.052 & $-0.053^{* *}$ \\
Male & $-0.213^{* * *}$ & 0.039 & $-0.108^{* * *}$ & $-0.178^{* * *}$ & 0.048 & $-0.074^{* * *}$ \\
Political View & $-0.216^{* * *}$ & 0.012 & $-0.358^{* * *}$ & $-0.233^{* * *}$ & 0.015 & $-0.317^{* * *}$ \\
Comment Valence & $0.090^{* * *}$ & 0.026 & $0.070^{* * *}$ & $0.091^{* *}$ & 0.032 & $0.058^{* *}$ \\
Intercept & $5.112^{* * *}$ & 0.055 & $0.000^{* * *}$ & $4.574^{* * *}$ & 0.069 & $0.000^{* * *}$ \\
\hline Adjusted $\mathrm{R}^{2}$ & & 0.147 & & & 0.111 & \\
\hline${ }^{*} \mathrm{p}<.05 ;{ }^{* *} \mathrm{p}<.01 ;{ }^{* * *} \mathrm{p}<.001$ & & & & \\
\hline
\end{tabular}

4.1.2 H1b: People Are Less Motivated to Know More About Social Issues Related to News Posts with Political Hashtags. Similarly, when political hashtags are included in news posts, people are significantly less motivated to know more about related social issues (a .053 standard deviation decrease in motivation to know more about social issues related to the news post). The control variables significantly contribute to decreased motivation to know more in a similar manner to the regression results for perception of social importance. Men, politically conservative individuals, 
and those who were shown negative comments significantly want to know less about social issues related to the news post compared to their counterparts who are female, politically liberal, and from the positive-comment group.

4.1.3 H2a: People Find News Posts More Partisan When Political Hashtags Are Included in News Posts. On the other hand, political hashtags in news posts is a significant positive predictor of negative perception. Based on our regression results for negative perception (Table 5), presence of political hashtags significantly increases people's perception that the partisan undertone of the news post is obvious (a .063 standard deviation increase in perception of partisan bias). In other words, when political hashtags are included in news post, people perceive the news post to be more partisan.

Overall, control variables also significantly contribute to perception of partisan bias towards the news post. Compared to women and the politically liberal, perception of partisan bias is significantly higher across males and the politically conservative. Comment valence, however, has no significant effect on perception of partisan bias.

Table 5. Results of standardized linear regression model examining how the presence of political hashtags in news posts affect negative perception towards the news post in terms of perception of partisan bias $(\mathrm{H} 2 \mathrm{a})$ and topic controversy $(\mathrm{H} 2 \mathrm{~b})$.

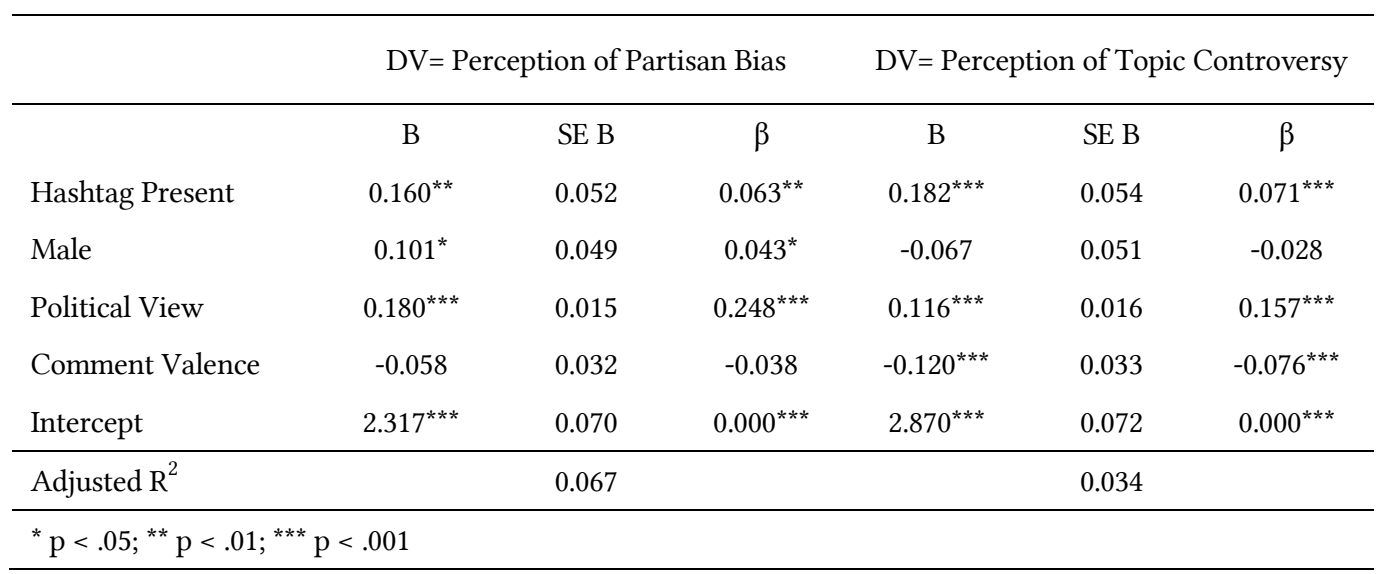

4.1.4 H2b: People Find the Topic of the News Post More Controversial When Political Hashtags Are Included in News Posts. Similarly, when political hashtags are included in news posts, people find the news topic to be significantly more controversial (a .071 standard deviation increase in perception of topic controversy). Furthermore, those who are politically conservative and were shown positive comments find the news topic more controversial than those who are liberal and were shown negative comments in the news post. There is no significant difference across gender in perception of topic controversy.

4.1.5 Negative Perception Mediates Political Hashtags' Impact on Motivation for Engagement. So far, our findings show that the presence of political hashtags in news posts decreases motivation for engagement (H1) while increasing negative perception (H2). When political hashtags are included in news posts, people find the social issue discussed in the news post to be less socially important (H1a) and are less motivated to know more about social issues related to the news post (H1b). Furthermore, presence of hashtags in news posts leads people to believe that the news post is more partisan (H2a) and controversial (H2b).

Prior research shows that not only are people turned off by partisanship in news coverage, but that hyper-partisanship is linked with less motivation to engage with social issues $[2,46]$. Assuming that the quality of democracy is "partly a function of the extent to which people are 
engaged with politics through social issues" [46], we further examine whether negative perception associated with political hashtags is the mechanism that explains political hashtags' negative influence on motivation for engagement. In other words, we assess whether the reason political hashtags turn people off is due to the perception of partisan bias and topic controversy induced by political hashtags.

Hence, to further investigate how perception of partisan bias and controversy towards news posts framed with political hashtags affect motivation for engagement, we conducted a mediation analysis. Using Mplus [44], we constructed a path model, controlling for gender, political view, and comment valence. Figure 3 shows the path model with the significant standardized path coefficients ${ }^{4}$. The resulting fit indices show that our model indicated good fit $\left(\chi^{2}(6)=66.185, p<\right.$ 0.001; Comparative Fit Index $=0.956$; Root Mean Square Error of Approximation $=0.071[0.052$ 0.057]; Standardized Root Mean Square Residual= 0.026) [27, 58].

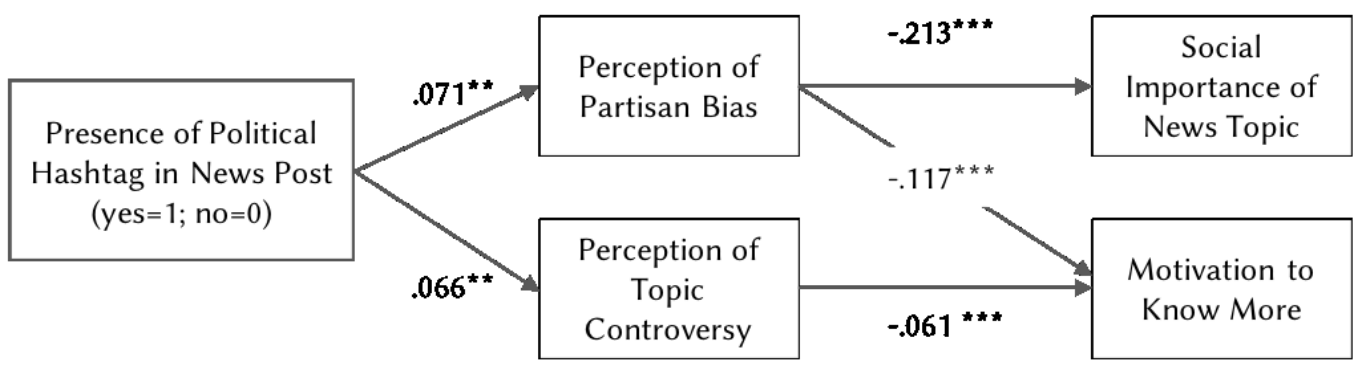

Fig. 3. Path model showing standardized coefficients $\left({ }^{*} \mathrm{p}<.05 ;{ }^{* *} \mathrm{p}<.01 ;{ }^{* *} \mathrm{p}<.001\right)$ demonstrate that presence of political hashtags in news posts predicts an increase in a person's negative perception (Partisan Bias \& Controversy) towards the news post, which in turn, predicts decreased motivation for engagement (Social Importance and Know More).

Our path model demonstrates that when political hashtags are included in news posts, participants find the hashtagged news content more partisan $(\beta=.071$ or a .071 standard deviation increase in perception of partisan bias), which in return makes people perceive the news topic to be less socially important $(\beta=-.213$ or a .213 standard deviation decrease in perception of social importance), as well as less motivated to know more about social issues related to the news post ( $\beta$ $=-.117)$. In fact, the impact of political hashtags in news posts on perception of social importance of news topic is fully mediated by perception of partisan bias (indirect effect of hashtag presence on social importance mediated by partisan bias $=-.015, \mathrm{p}=.002)$. In other words, political hashtags in news posts significantly reduces people's perception that the news topic is socially important, due to the perception that the hashtagged news post is partisan.

Similarly, political hashtags in news posts increase people's perception that the news topic is controversial $(\beta=.066)$, which in turn demotivates people to know more about social issues related to the news post $(\beta=-.061)$. The impact of political hashtags in news posts on knowing more about related social issues is fully mediated by perception of partisan bias (indirect effect of hashtag presence on motivation to know more mediated by partisan bias $=-.008, \mathrm{p}=.03$ ) and topic controversy (indirect effect of hashtag presence on motivation to know more mediated by topic controversy $=-.004, \mathrm{p}=.005)$. In other words, perceptions of partisan bias and topic controversy are

\footnotetext{
${ }^{4}$ Following standard practice for path analyses [42], we first estimated our path model including a direct path between hashtag presence and social importance of news topic and a direct path between hashtag presence and motivation to know more about related social issues. The direct effects were not significant, thus the subsequent final model we estimated did not include those direct effects. A direct path between perception of topic controversy and perception of social importance of news topic was not included in the final model for the same reason.
} 
the mechanisms through which people are less motivated to know more about social issues related to the hashtagged news posts.

Overall, our path model demonstrates that negative perception through partisan bias and topic controversy is the mechanism through which people perceive the hashtagged news posts to be less socially important and are less motivated to know more about related news posts.

\subsection{RQ2: Among the Politically Moderate, News Posts with Political Hashtags Were Perceived Significantly More Partisan}

In order to compare how the presence of political hashtags shapes perception of partisan bias between the politically moderate and those who are more politically extreme, we used kernel density estimate $(\mathrm{KDE})$ to visualize the distribution of responses on perception of partisan bias towards news posts across three political groups - those who identified as "Extremely Liberal", "Moderate or Middle of the Road", and "Extremely Conservative" (Figure 4).

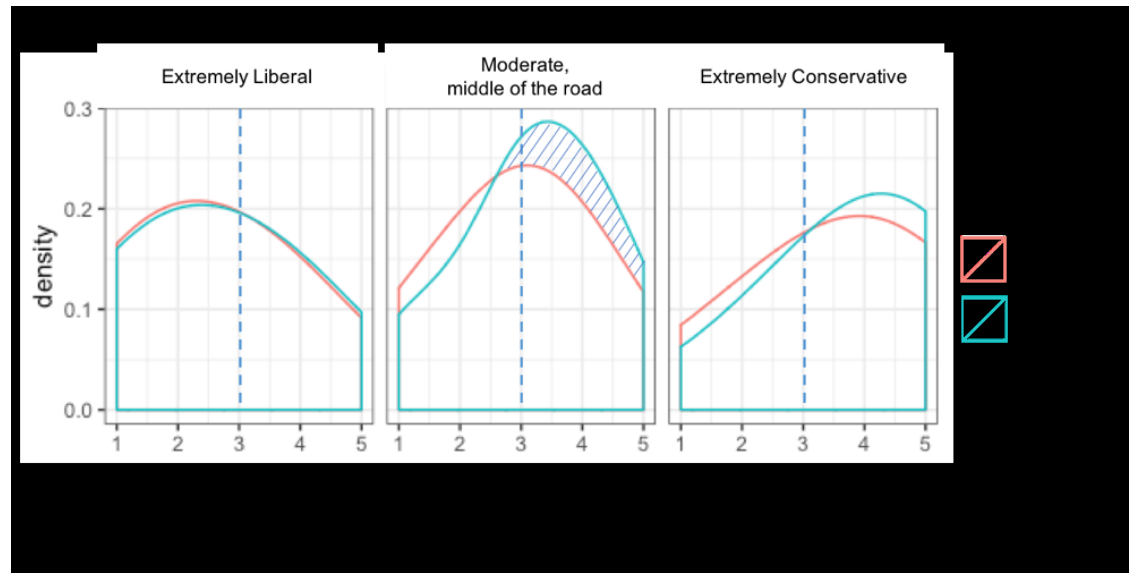

Fig. 4. Kernel density estimate ( $n=742)$ comparing individual differences in perception of partisan bias of news posts across three political groups (Extremely Liberal, Moderate, \& Extremely Conservative) when hashtags are present (blue) vs. absent (red) in news posts. Higher numbers on the $x$-axes represent a greater shift toward increased perception of partisan bias.

The distribution of responses among those who identify as extremely liberal for both hashtag and control groups (Fig.4, left) are left-skewed, meaning in general, these folks tend to regard news posts about gender and racial issues from our experiment less partisan regardless of hashtag presence. By contrast, for the extremely conservative participants (Fig.4, right), the distribution of responses is more right-skewed. However, the distribution for the hashtag group (blue) peaks higher and is even more right-skewed than the non-hashtag group (red), implying that hashtag presence makes extremely conservative people perceive the news as more partisan.

While these are somewhat expected results, what is really interesting is the people in the middle (Fig.4, center). Among those who identify as politically moderate, those who saw news posts with hashtags (blue) perceive news posts to be more partisan than those shown news posts without hashtags (red) as illustrated in the shaded gap between the blue and red distributions. To test for significance, an independent t-test was conducted to compare perception of partisan bias towards news posts between the control and the hashtag groups among the politically moderate. Results show a significant difference in perception of partisan bias for the control $(M=2.935$, $\mathrm{SD}=1.298)$ and hashtag groups $(\mathrm{M}=3.16, \mathrm{SD}=1.251) ; \mathrm{t}(417)=-1.9449, \mathrm{p}=0.05)$.

4.2.1 Among the Politically Moderate, There Are Key Differences in Discourse Patterns Between the Hashtag and Control Groups in Their Comments on News Posts. In Figures 5A and 5B, we show 
two survey scenarios - one containing the hashtag (left) and one without (right). ${ }^{5}$ In Table 6, we show comments written by respondents in reaction to the news posts shown in respective scenarios. Only respondents who identified as politically moderate are included.

4.2.2 Greater Focus on the Politics of the Hashtag \& Less Attention Directed Towards Social Issues. When comparing respondent comments between the hashtag and control groups what is immediately noticeable is that those who were shown hashtags in the news posts are more focused on the politics of the hashtag rather than the social issues related to it. For example, among respondents in the hashtag group, not once, are the terms "sexual harassment" or "sexual assault" - social topics central to \#MeToo, mentioned in their comments. Instead, their discussions primarily pivot around the hashtag itself (e.g., "The MeToo movement is ridiculous", "MeToo is a hoax against men?"). By contrast, comments from respondents in the control group topically centered around sexual harassment or assault (e.g., "Some people are afraid to report any harassment or assaults", "It is quite alarming that sexual harassment and assault occur at such a high rate", "men...experience sexual harassment as well and not just the women"). In fact, nearly all of the comments in the control group either mention sexual harassment, experience, or assault in their reaction to the news post.

4.2.3 Difference in Interpretation of News Content \& Emotional Intensity of Linguistic Expression. Respondents from both groups react to the same details shown in the news post; however, the interpretation as well as the language used to interpret the content are vastly different between the two groups. Comments from the hashtag group refer to the statistics as "load of crap" or "load of shit" while reactions from the control group are much more nuanced and subdued: "My first reaction is that these numbers are really high" or "Frankly, these numbers seem low to me". Furthermore, the linguistic style of comments from the hashtag group are more emotionally intense, marking extreme reactions towards the news content (e.g., "43\%of men?!?!?!”). Even those who seem to be in favor of the hashtag movement use aggressive language to convey support of the movement and refer to those against it as "You idiots", claiming, "there's a reason why [\#MeToo] $\mathrm{f}^{* * * *}$ ng exists, dimwits!!".

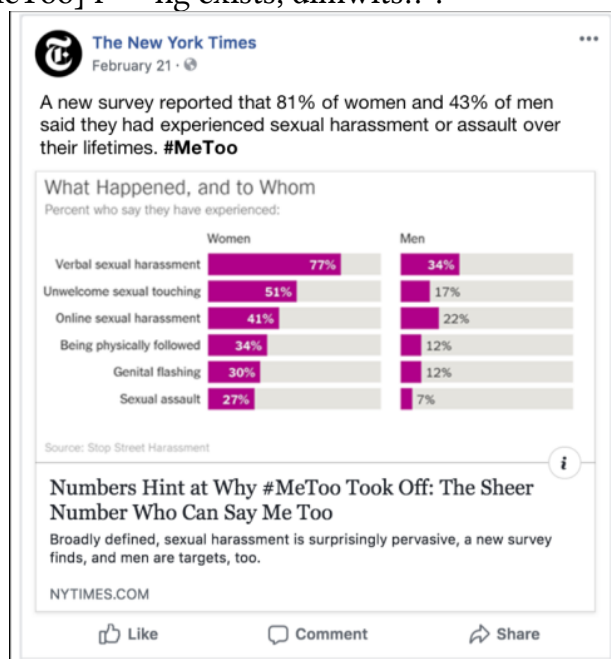

Fig 5A. News post with \# (hashtag group)

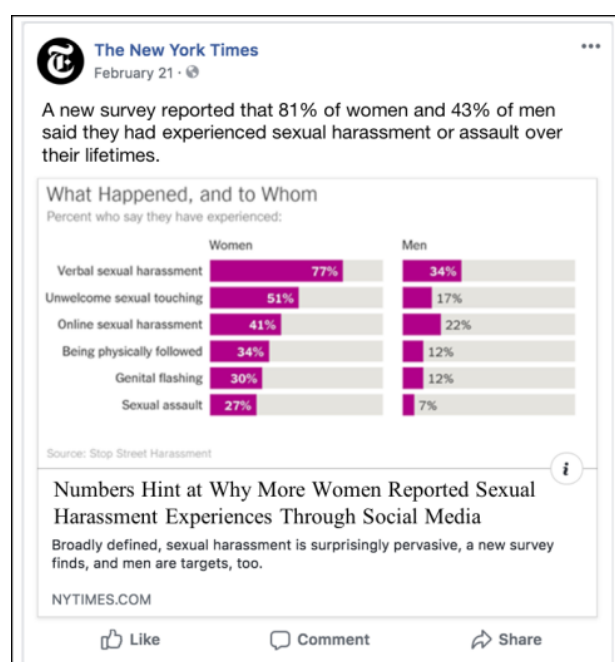

Fig 5B. News post without \# (control group)

\footnotetext{
${ }^{5}$ Everything in the hashtag scenario post on the left is identical to the original news post published on Facebook (Figure B, Appendix), except for the bolded \#MeToo hashtag in the post text, which was not included in the original post.
} 
Table 6. Comment responses to news posts with and without hashtags to the article in Figure 5.

\begin{tabular}{|c|c|}
\hline $\begin{array}{l}\text { Comment responses to news post } \\
\text { with hashtags }\end{array}$ & $\begin{array}{l}\text { Comment responses to news post } \\
\text { without hashtags }\end{array}$ \\
\hline $\begin{array}{l}\text { The \#MeToo topic is turning into } \\
\text { something like the Kardashians. You } \\
\text { can't look at the news without both of } \\
\text { them headlining things. It is an } \\
\text { important issue, but I am getting tired } \\
\text { of seeing it over and over. }\end{array}$ & $\begin{array}{l}\text { I think the men's percentage is higher, } \\
\text { but more women report this kind of stuff } \\
\text { than men. Men should be more open about } \\
\text { the stuff they go through as well. }\end{array}$ \\
\hline $\begin{array}{l}\text { The MeToo movement is ridiculous. People } \\
\text { are best off when they report incidents } \\
\text { to the police. Rehashing incidents years } \\
\text { later on a public forum just results in } \\
\text { witch hunts. These incidents are personal } \\
\text { and should be resolved with more dignity. }\end{array}$ & $\begin{array}{l}\text { Giving a platform and voice to victims } \\
\text { via social media is a great way to share } \\
\text { one's experience when one is to } \\
\text { uncomfortable to do so publicly. Some } \\
\text { people are too afraid to report any } \\
\text { harassment or assaults due to being } \\
\text { labeled a liar so I'm glad there's a way } \\
\text { to keep track of these instances without } \\
\text { them going unheard. }\end{array}$ \\
\hline $\begin{array}{l}\text { This is a load of crap on a number of } \\
\text { levels. When broadly defined, Pluto was } \\
\text { a planet too. The numbers on this topic } \\
\text { have been inflated before and it appears } \\
\text { they have again. }\end{array}$ & $\begin{array}{l}\text { To say one gender over another } \\
\text { experiences harassment more is an } \\
\text { understatement! I feel it happens just as } \\
\text { much for each gender, but more are afraid } \\
\text { to say anything. }\end{array}$ \\
\hline $\begin{array}{l}\text { I'm sorry - 43\%of men?!?!?! Now that's a } \\
\text { load of shit. Especially 17\% of } \\
\text { "unwelcomed sexual touching". This } \\
\text { article reads "FAKE NEWS". }\end{array}$ & $\begin{array}{l}\text { It is quite alarming that sexual } \\
\text { harassment and assault occur at such a } \\
\text { high rate among people. I suspect that } \\
\text { the numbers for men may be lower than the } \\
\text { truth due to the fact that society } \\
\text { presents the stigma that if a man reports } \\
\text { a sexual assault or harassment that } \\
\text { occurred to them, then they will be } \\
\text { viewed as being weak. Maybe we need to } \\
\text { teach children at a younger age what is } \\
\text { and what isn't appropriate to say and do } \\
\text { to another person instead of ignoring the } \\
\text { obvious fact that there is a problem in } \\
\text { our society. }\end{array}$ \\
\hline $\begin{array}{l}\text { And you idiots still think \#MeToo is a } \\
\text { hoax against men? C'mon, some people may } \\
\text { be taking advantage of the movement, but } \\
\text { there's a reason why it } \text { th**ng exists }^{* *} \text { dimwits!! }\end{array}$ & $\begin{array}{l}\text { My first reaction is that these numbers } \\
\text { are really high. Most women are sexually } \\
\text { harassed, and almost half of men are } \\
\text { sexually harassed. That's remarkable and } \\
\text { sad. Looks like a big social problem. }\end{array}$ \\
\hline I don't care about this. & $\begin{array}{l}\text { I like that they are showing the } \\
\text { statistics of the percentage of men that } \\
\text { experience sexual harassment as well and } \\
\text { not just the women. }\end{array}$ \\
\hline \multirow{2}{*}{$\begin{array}{l}\text { I don't believe this post is backed with } \\
\text { any real knowledge or fact }\end{array}$} & $\begin{array}{l}\text { I find the information listed in the } \\
\text { article to be non-biased. Frankly these } \\
\text { numbers seem low to me. }\end{array}$ \\
\hline & $\begin{array}{l}\text { I really want to understand more about } \\
\text { this phenomenon and why women are feeling } \\
\text { this way. }\end{array}$ \\
\hline
\end{tabular}


Furthermore, what is ironic is that the absence of \#MeToo in the news content actually promotes/ solicits the intended goal of the hashtag movement. In reaction to the news post, one commenter from the control group remarks, "Giving a platform and voice to victims via social media is a great way to share one's experience when one is to uncomfortable to do so publicly." Here, the commenter highlights in essence, the purpose of the \#MeToo movement and how it is positively affecting survivors and raising much-needed awareness. By contrast, when the news content is framed with the hashtag, a respondent criticizes the online movement describing how "Rehashing incidents years later on a public forum just results in witch hunts".

4.2.4 Difference in Topic Engagement \& Perception of Content Credibility. Another interesting difference between the two groups is the willingness to engage on topics associated with the online movement. In the hashtag group, people repeatedly mention the hashtag without substantially engaging with relevant social issues. When such behavior is replicated on social media, this may amplify how much one is exposed to a constant, yet substance-wise, empty reiteration of the hashtag:

"\#MeToo topic is turning into something like the Kardashians. You can't look at the news without both of them headlining things".

As a result, for this respondent, even though "It is an important issue", she remarked, I am getting tired of seeing it over and over". On the other hand, in contrast to the apathy expressed by those in the hashtag group (e.g., "I don't care about this"), control group participants expressed more willingness to engage on relevant social topics (e.g., "I really want to understand more about this phenomenon and why women are feeling this way"). In fact, for some, the news post serves as the basis for prompting further action: "Maybe we need to teach children at a younger age what is and what isn't appropriate to say and do to another person".

Furthermore, the presence of hashtags is perceived as undermining the content credibility of news posts. Comments from the hashtag group expressed suspicion towards the news post as evident in claims, such as "I don't believe this post is backed with any real knowledge or fact" and "This article reads "FAKE NEWS". By contrast, comments from the control group were less skeptical: "I find the information listed in the article to be non-biased." What is particularly interesting here is that these comments tended to reflect opinions on the actual content of the news story rather than blanket assumptions about the story's bias or plausibility: "I like that they are showing the statistics of the percentage of men that experience sexual harassment as well and not just the women".

\subsection{RQ3: Repeated Exposure to Political Hashtags Increases Perception of Partisan Bias While Deterring Further Engagement on Social Issues Related to the News Post}

Our analysis of comments in RQ2 indicated that respondents from the hashtag group who criticized the partisan tone of news posts, frequently mentioned being "tired of" or "sick of" seeing such posts "that seemed to be everywhere", denoting the pervasiveness of hashtagged content. In this vein, we examine whether repeated exposures to political hashtags may influence perception of partisan biases as well. Assuming those who use Facebook more frequently are likely to have a higher chance of being exposed to these social media hashtags, we compared responses around perception of partisan bias across different levels of Facebook use - between those who were high (use $\mathrm{Fb}$ several times per day) versus low (less than once per week) intensity users.

We visualize this difference in Figure 6, which shows an interesting difference between the low and high-intensity users in terms of perception of partisan bias towards hashtagged news posts ${ }^{6}$. The distribution of high-intensity users in the hashtag group is visibly more skewed to the right compared to that of low-intensity users.

\footnotetext{
${ }^{6}$ For this KDE, we only used sample of high and low intensity Facebook users who were either shown hashtags or no hashtags in their news posts. Those who were shown positive or negative comments were excluded.
} 
Furthermore, among those who use Facebook less than once per week (Fig.6, left), the distribution of responses between the hashtag and the non-hashtag groups are similar, meaning perception of partisan bias is not really affected by presence of political hashtags. However, for those who use Facebook several times per day (Fig.6, right), the distribution of responses for participants who were shown hashtags (blue) is more skewed towards the right, in other words, perceive the news post as more partisan, compared to the control group (red), exemplified by the shaded gap.

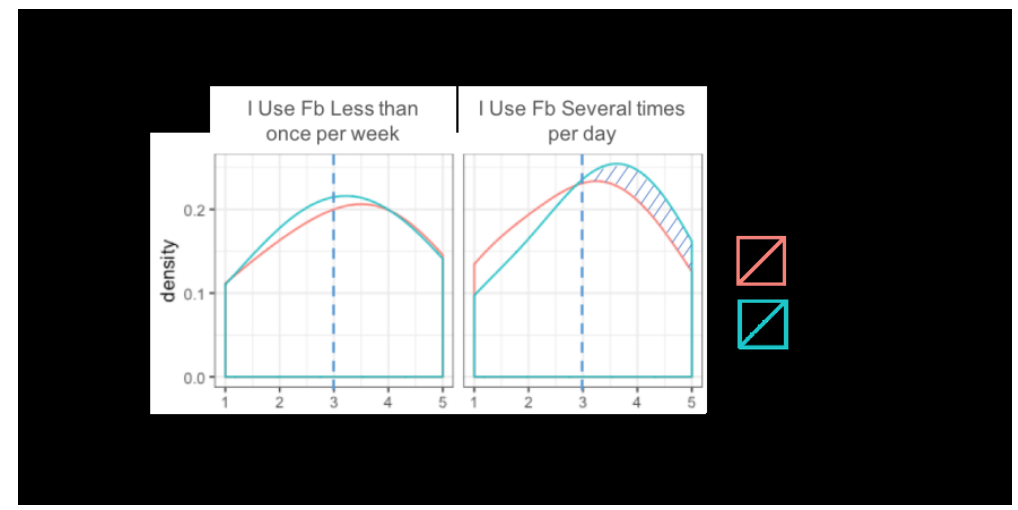

Fig. 6. Kernel density estimate $(n=894)$ comparing individual differences in perception of partisan bias towards news posts between low (Less than once per week) and high intensity (Several times per day) Facebook users when hashtags are present (blue) vs. absent (red).

In fact, an independent-samples t-test indicated that while the presence of hashtags did not significantly affect the perception of partisan bias among low-intensity Facebook users, there was a statistically significant difference between the hashtag and control groups among high-intensity users. Results show that across high-intensity Facebook users, there is a significant difference in perception of partisan bias between the control $(\mathrm{M}=2.956, \mathrm{SD}=1.260)$ and hashtag groups $(\mathrm{M}=3.275, \mathrm{SD}=1.250) ; \mathrm{t}(758)=-3.225, \mathrm{p}<.001)$.

4.3.1 Repeated Exposure to Political Hashtags May Deter Social Engagement. Among highintensity Facebook users from the hashtag group, respondents commonly expressed exasperation around "hearing about any movements and us labeling them with some hashtags to just bring people out and to get attention!" (Male, 26, Politically Moderate). Similarly, in reaction to a news post containing \#BlackLivesMatter, one participant remarked that despite the positive intentions of the hashtag movement (e.g. "helping people of color"), perpetuated exposure turned people off:

"Glad that the movement is helping people of color, but I do feel like, with anything, if you shove it in peoples' faces long enough, they are going to get annoyed"(Female, 21, Very Liberal).

Such repeated exposure to political hashtags can lead to a sense of saturation and the false drumming up of interest in hashtag movements. From the perspective of another commenter who uses Facebook several times a day, such interest is perceived as forced and overstated.

"Honestly, social media is generating something akin to false positivity, or inflated enthusiasm. I am so entirely sick of this NPR American bullshit. I am very liberal; I am not racist or anything but it's just too much. If I see another post on the Internet about someone being a "Strong Woman", I'm going to lose my fucking mind. No one is benefiting from this. We are not really more "informed" as a society now that the internet is here... less information and more of the same opinions on the same side of the line...As an intellectual I cannot cosign this mentality" (Female, 35, Liberal). 
Here, the respondent who identifies as liberal is commenting on a news post hashtagged with \#BlackLivesMatter. This is a particularly striking statement, in that this commenter reports being inclined to agree with the social issue, but is so turned off by the hashtag that she is no longer sympathetic to the issue or the movement. If anything, the language in this comment sounds like someone who would consider themselves an opponent rather than an ally.

\section{DISCUSSION}

\subsection{Effects of Political Hashtags on Identity Politics, Critical Dialogue, \& Social Movements}

HCI work have shown that users from different groups will interpret political hashtags differently based on their social identities, such as race, gender, and even profession [26, 33, 36, 64]. Studies and news reports also show that solidarity and backlash around political hashtag movements are strongly tied to multiple identities $[34,55]$. Hence, dialogue framed with political hashtags can easily manifest as a struggle for power in controlling discourse around moralized issues between different racial and political groups who interpret the hashtag differently [13, 26, 34].

Our findings show that respondents who were exposed to news posts framed by hashtags found the news significantly more partisan and controversial than those who did not see hashtagged content. Comments from respondents also demonstrate that news content framed with political hashtags register as issues strongly pertaining to identity politics. This implies that political hashtags tend to tribalize social issues, catering to one side or the other. This is problematic, because research shows that when competing tribes are so vividly identified, it makes the sense of the "other" even stronger [41], reinforcing rather than bridging different perspectives across the spectrum [65]. The capacity to listen to those who agree with oneself is a critical aspect of constructive civil discourse. Political hashtags, however, seem to make it harder for people to find common-ground perspectives around social issues embodied by them.

Relatedly, scholars in political sociology have found that partisan identification tends to drown out attention to details around policy issues [31]. People who perceived the news as more partisan (due to the presence of political hashtags) reported that they also perceived the news content as less important and were less inclined to know more about related social topics. These findings suggest that in the long-run, political hashtags may ultimately polarize and intensify political views, weakening the quality of democratic discourse on important social issues.

Social movement theory further suggests that in order for social movements to be successful (e.g., effecting change in social discourse and policy), activists need to mobilize a broader audience beyond "passionate enthusiasts" $[4,19]$. In other words, impact needs to spread beyond those initially aligned with a movement. However, our findings show that politically moderate people are turned off by political hashtags. Compared to news posts without hashtags, these "middle of the road" people perceive hashtagged news posts as more partisan and employed negative and emotionally charged expressions in their open-ended comments. Respondents in this group not only reported a lack of willingness engage on the news content framed with hashtags, but also questioned the credibility of what they saw in the news post - further suggesting that the hashtags may be an obstacle to mobilizing moderate groups around a social issue.

Hence, prior work that operationalized the number of frequently co-occurring hashtags (e.g., \#BlackLivesMatter, \#whatiswrongwithoursystem) to show that people develop deeper and more personalized connections to key social issues over time [10] may be exclusively portraying those who were intrinsically inclined to engage with the hashtags (and relevant social issues) in the first place. As such, political hashtags may in the long-run be detrimental for activists to gain a wider more universal appeal for their cause.

Social movement theorists studying social media posit that SNS can dramatically speed up the awareness in the "preliminary stage" of social movements [7, 69]. This is possible, because through SNS artifacts like political hashtags, "issue awareness can spread at the speed of a click, with 
thousands of people across the globe becoming informed at the same time"[41]. However, our findings add a layer of complexity to these prior insights. Does the rapid awareness enabled by political hashtags across social media lead to initial mobilization that may backfire over time? Further work should investigate possible tipping points for hashtag effects and explore the relationship between early exposure/mobilization and longer term saturation/disinterest.

Our results indicate that repeated exposure to political hashtags may deter people from wanting to know more about key social issues related to the hashtag. Those who use Facebook frequently are more influenced by hashtags in their perception of partisan bias of news posts compared to low-intensity Facebook users. Respondent comments from the hashtag group also directly state that repeated exposure to hashtags can become a blanket turn off. These findings suggest that research should rethink methodological techniques that quantify success and engagement through hashtags' frequency. Findings from our work suggest that such quantified approaches can lead to a skewed understanding of social media's influence on democratic engagement and discourse.

\section{CONCLUSION}

Our work contributes to the current literature on political hashtags by elucidating the implicit effects of hashtags on passive consumers of news media. People found the news more partisan and controversial when hashtags were included. Overall, negative perception through partisan bias and topic controversy is the mechanism through which people perceive the hashtagged news posts to be less socially important and are less motivated to know more about related social issues. Furthermore, compared to news posts without political hashtags, news with hashtags were perceived significantly more partisan among those who use Facebook more often, as well as those who identify as politically moderate. There were also significant differences in discourse patterns around how politically moderate respondents engaged with the news content in their comments between the hashtag and control groups.

\section{LIMITATIONS}

Prior literature shows that the political nature of media source bias might influence commenting behavior [55]. For our data source, we chose only two publishers - NYT and NPR. In selecting news publishers with high factual reporting [24] and consistent posting of topically diverse articles on their Facebook page, these two mainstream news publishers were most suitable for the purpose of our study. Yet, although relatively close to mainstream, both NYT and NPR are considered left-centered news publishers [46, 47]. Hence, these media sources may not be representative of news outlets consumed by more politically conservative participants. This could potentially impact our findings given that participants who identify as politically conservative may have presumptions about these news outlets in the first place. To partially address this issue, we focused on understanding reactions from those who identified as politically moderate through RQ2 in our work. 


\section{APPENDIX}

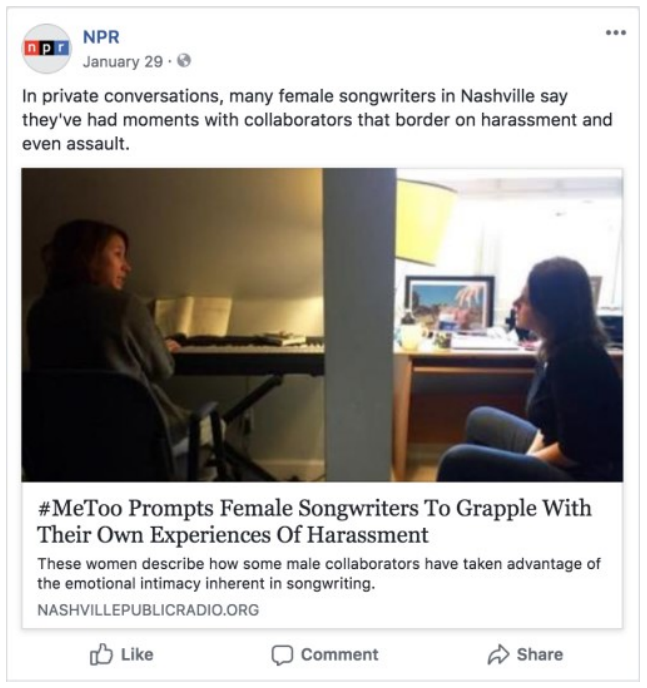

Fig. A.

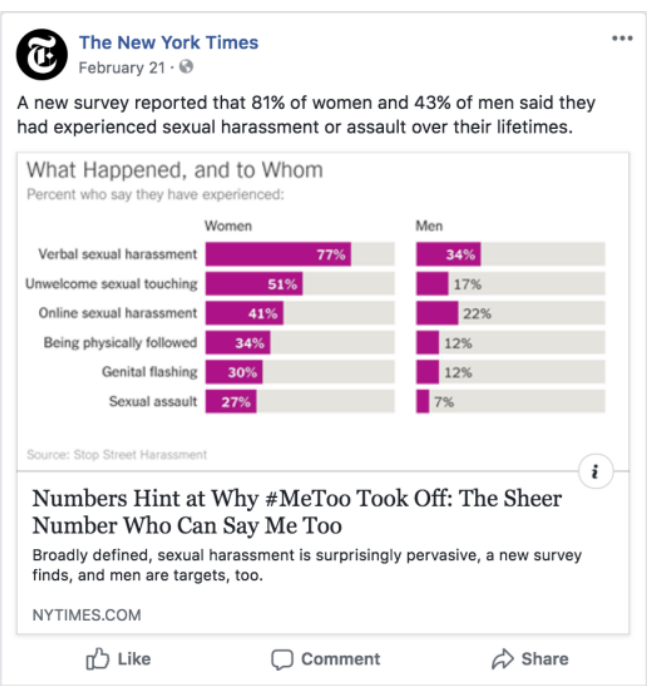

Fig. B. 
Table A. Demographics of Survey Participants $(\mathrm{n}=1979)$

\begin{tabular}{|c|c|c|c|}
\hline Category & Demographic Traits & Freq. & $\%$ \\
\hline \multirow{4}{*}{ Gender } & Male & 1027 & $52 \%$ \\
\hline & Female & 929 & $47 \%$ \\
\hline & Non-Binary & 14 & $1 \%$ \\
\hline & Prefer not to answer & 9 & $0 \%$ \\
\hline \multirow{7}{*}{ Age } & $18-27$ & 458 & $23 \%$ \\
\hline & $28-37$ & 776 & $39 \%$ \\
\hline & $38-47$ & 379 & $19 \%$ \\
\hline & $48-57$ & 226 & $11 \%$ \\
\hline & $58-67$ & 114 & $6 \%$ \\
\hline & $68-77$ & 24 & $1 \%$ \\
\hline & $78-87$ & 2 & $0 \%$ \\
\hline \multirow{7}{*}{ Political View } & Extremely Liberal & 221 & $11 \%$ \\
\hline & Very Liberal & 424 & $21 \%$ \\
\hline & Slightly Liberal & 287 & $15 \%$ \\
\hline & Moderate, Middle of the Road & 419 & $21 \%$ \\
\hline & Slightly Conservative & 256 & $13 \%$ \\
\hline & Very Conservative & 270 & $14 \%$ \\
\hline & Extremely Conservative & 102 & $5 \%$ \\
\hline \multirow{6}{*}{ Education } & High school incomplete or less & 12 & $1 \%$ \\
\hline & High school graduate or GED & 168 & $8 \%$ \\
\hline & $\begin{array}{l}\text { Some college (community college, associate's } \\
\text { degree) }\end{array}$ & 605 & $31 \%$ \\
\hline & Four year college degree/bachelor's degree & 793 & $40 \%$ \\
\hline & $\begin{array}{l}\text { Some postgraduate or professional schooling, no } \\
\text { postgraduate degree }\end{array}$ & 89 & $4 \%$ \\
\hline & $\begin{array}{l}\text { Postgraduate or professional degree, including } \\
\text { master's, doctorate, medical or law degree }\end{array}$ & 312 & $16 \%$ \\
\hline
\end{tabular}

\section{REFERENCES}

[1] Albright, J. 2016. The \#Election2016 Micro-Propaganda Machine. Jonathan Albright.

[2] Bail, C.A., Argyle, L.P., Brown, T.W., Bumpus, J.P., Chen, H., Hunzaker, M.B.F., Lee, J., Mann, M., Merhout, F. and Volfovsky, A. 2018. Exposure to opposing views on social media can increase political polarization. Proceedings of the National Academy of Sciences. 115, 37 (Sep. 2018), 9216-9221. DOI:https://doi.org/10.1073/pnas.1804840115.

[3] Bates, L. 2015. Why do fewer women tweet political party hashtags? The Guardian.

[4] Benford, R.D. and Snow, D.A. 2000. Framing processes and social movements: An overview and assessment. Annual review of sociology. 26, 1 (2000), 611-639.

[5] Bennett, W.L. 2012. The Personalization of Politics: Political Identity, Social Media, and Changing Patterns of Participation. The ANNALS of the American Academy of Political and Social Science. 644, 1 (Nov. 2012), 20-39. DOI:https://doi.org/10.1177/0002716212451428. 
[6] Bennett, W.L. and Segerberg, A. 2011. Digital Media and the Personalization of Collective Action. Information, Communication \& Society. 14, 6 (Sep. 2011), 770-799. DOI:https://doi.org/10.1080/1369118X.2011.579141.

[7] Blumer, H. 1969. Principles of sociology. Barnes \& Noble.

[8] Bonilla, Y. and Rosa, J. 2015. \# Ferguson: Digital protest, hashtag ethnography, and the racial politics of social media in the United States. American Ethnologist. 42, 1 (2015), 4-17.

[9] Bonilla, Y. and Rosa, J. 2015. \#Ferguson: Digital protest, hashtag ethnography, and the racial politics of social media in the United States: \#Ferguson. American Ethnologist. 42, 1 (Feb. 2015), 4-17. DOI:https://doi.org/10.1111/amet.12112.

[10] Booten, K. 2016. Hashtag Drift: Tracing the Evolving Uses of Political Hashtags Over Time. Proceedings of the 2016 CHI Conference on Human Factors in Computing Systems (New York, NY, USA, 2016), 2401-2405.

[11] Bruns, A. and Burgess, J.E. 2011. The use of Twitter hashtags in the formation of ad hoc publics. Proceedings of the 6th European Consortium for Political Research (ECPR) General Conference 2011 (University of Iceland, Reykjavik, Aug. 2011).

[12] Bruns, A., Highfield, T. and Burgess, J. 2013. The Arab Spring and social media audiences: English and Arabic Twitter users and their networks. American Behavioral Scientist. 57, 7 (2013), 871-898.

[13] Carney, N. 2016. All Lives Matter, but so Does Race: Black Lives Matter and the Evolving Role of Social Media. Humanity \& Society. 40, 2 (May 2016), 180-199. DOI:https://doi.org/10.1177/0160597616643868.

[14] Chokshi, N. 2016. How \#BlackLivesMatter Came to Define a Movement. The New York Times.

[15] Clark, R. 2016. "Hope in a hashtag": the discursive activism of \#WhyIStayed. Feminist Media Studies. 16, 5 (Sep. 2016 ), 788-804. DOI:https://doi.org/10.1080/14680777.2016.1138235.

[16] Cunha, E., Magno, G., Gonçalves, M.A., Cambraia, C. and Almeida, V. 2014. He Votes or She Votes? Female and Male Discursive Strategies in Twitter Political Hashtags. PLOS ONE. 9, 1 (Jan. 2014), e87041. DOI:https://doi.org/10.1371/journal.pone.0087041.

[17] Dahlberg, L. 2001. The Internet and democratic discourse: Exploring the prospects of online deliberative forums extending the public sphere. Information, Communication \& Society. 4, 4 (2001), 615-633.

[18] Diakopoulos, N. and Naaman, M. 2011. Towards Quality Discourse in Online News Comments. Proceedings of the ACM 2011 Conference on Computer Supported Cooperative Work (New York, NY, USA, 2011), 133-142.

[19] Edwards, B. and McCarthy, J.D. 2007. Resources and Social Movement Mobilization. The Blackwell Companion to Social Movements. John Wiley \& Sons, Ltd. 116-152.

[20] Friedman, A. Hashtag journalism. The pros and cons to covering Twitter's trending topics. Columbia Journalism Review.

[21] Garber, M. 2014. The Difference Between Ferguson and \#Ferguson. The Atlantic.

[22] Garza, A. A Herstory of the \#BlackLivesMatter Movement by Alicia Garza. 5.

[23] Gee, J.P. 2014. An Introduction to Discourse Analysis: Theory and Method. Routledge.

[24] Glader, P. 10 Journalism Brands Where You Find Real Facts Rather Than Alternative Facts. Forbes.

[25] Glenski, M. and Weninger, T. 2017. Rating Effects on Social News Posts and Comments. ACM Trans. Intell. Syst. Technol. 8, 6 (Jul. 2017), 78:1-78:19. DOI:https://doi.org/10.1145/2963104.

[26] Hadgu, A.T., Garimella, K. and Weber, I. 2013. Political Hashtag Hijacking in the U.S. Proceedings of the 22Nd International Conference on World Wide Web (New York, NY, USA, 2013), 55-56.

[27] Harlow, S. 2012. Social media and social movements: Facebook and an online Guatemalan justice movement that moved offline. New Media \& Society. 14, 2 (Mar. 2012), 225-243. DOI:https://doi.org/10.1177/1461444811410408.

[28] Holcomb, J., Gross, K. and Mitchell, A. 2011. How Mainstream Media Outlets Use Twitter. Pew Research Center Journalism \& Media.

[29] Howard, P.N., Duffy, A., Freelon, D., Hussain, M.M., Mari, W. and Maziad, M. 2011. Opening closed regimes: what was the role of social media during the Arab Spring? Available at SSRN 2595096. (2011).

[30] Huang, J., Thornton, K.M. and Efthimiadis, E.N. 2010. Conversational tagging in twitter. Proceedings of the 21st ACM conference on Hypertext and hypermedia (2010), 173-178.

[31] Huddy, L., Mason, L. and Aarøe, L. 2015. Expressive Partisanship: Campaign Involvement, Political Emotion, and Partisan Identity. American Political Science Review. 109, 1 (Feb. 2015), 1-17. DOI:https://doi.org/10.1017/S0003055414000604.

[32] Jackson, S.J., Bailey, M. and Foucault Welles, B. 2017. \# GirlsLikeUs: Trans advocacy and community building online. New Media \& Society. (2017), 1461444817709276.

[33] Jackson, S.J. and Foucault Welles, B. 2016. \# Ferguson is everywhere: initiators in emerging counterpublic networks. Information, Communication \& Society. 19, 3 (2016), 397-418.

[34] Jackson, S.J. and Foucault Welles, B. 2015. Hijacking\# myNYPD: Social media dissent and networked counterpublics. Journal of Communication. 65, 6 (2015), 932-952.

[35] Kalmoe, N.P. 2014. Fueling the Fire: Violent Metaphors, Trait Aggression, and Support for Political Violence. Political Communication. 31, 4 (Oct. 2014), 545-563. DOI:https://doi.org/10.1080/10584609.2013.852642. 
[36] Kitzie, V. and Ghosh, D. 2015. \#Criming and \#Alive: Network and Content Analysis of Two Sides of a Story on Twitter. Proceedings of the 78th ASIS\&T Annual Meeting: Information Science with Impact: Research in and for the Community (Silver Springs, MD, USA, 2015), 41:1-41:10.

[37] Lee, E.-J. 2012. That's Not the Way It Is: How User-Generated Comments on the News Affect Perceived Media Bias. Journal of Computer-Mediated Communication. 18, 1 (Oct. 2012), 32-45. DOI:https://doi.org/10.1111/j.10836101.2012.01597.x.

[38] Lehmann, J., Gonçalves, B., Ramasco, J.J. and Cattuto, C. 2012. Dynamical classes of collective attention in twitter. Proceedings of the 21st international conference on World Wide Web (2012), 251-260.

[39] Li, H., Bora, D., Salvi, S. and Brady, E. 2018. Slacktivists or Activists?: Identity Work in the Virtual Disability March. Proceedings of the 2018 CHI Conference on Human Factors in Computing Systems (New York, NY, USA, 2018), 225:1-225:13.

[40] Lin, Y.-R., Margolin, D., Keegan, B., Baronchelli, A. and Lazer, D. 2013. \#Bigbirds Never Die: Understanding Social Dynamics of Emergent Hashtag. arXiv:1303.7144 [physics]. (Mar. 2013).

[41] Little, W. 2014. Introduction to Sociology.

[42] Loehlin, J.C. 1987. Latent variable models: An introduction to factor, path, and structural analysis. Lawrence Erlbaum Associates, Inc.

[43] Loza, S. Hashtag Feminism, \#SolidarityIsForWhiteWomen, and the Other \#FemFuture. Ada: A Journal of Gender, New Media, and Technology. 5. DOI:https://doi.org/10.7264/N337770V.

[44] Manikonda, L., Beigi, G., Liu, H. and Kambhampati, S. 2018. Twitter for sparking a movement, reddit for sharing the moment:\# metoo through the lens of social media. arXiv preprint arXiv:1803.08022. (2018).

[45] Marcotte, A. 2017. Conservative backlash against \#MeToo is coming, and soon. Salon.

[46] Media Bias / Fact Check: New York Times: https://mediabiasfactcheck.com/new-york-times/. Accessed: 2018-04-17.

[47] Media Bias / Fact Check: NPR (National Public Radio): https://mediabiasfactcheck.com/npr/. Accessed: 2019-06-27.

[48] Michie, L., Balaam, M., McCarthy, J., Osadchiy, T. and Morrissey, K. 2018. From Her Story, to Our Story: Digital Storytelling as Public Engagement around Abortion Rights Advocacy in Ireland. Proceedings of the $2018 \mathrm{CHI}$ Conference on Human Factors in Computing Systems - CHI '18 (Montreal QC, Canada, 2018), 1-15.

[49] NW, 1615 L. St, Suite 800Washington and Inquiries, D. 20036USA202-419-4300 | M.-857-8562 | F.-419-4372| M. How Americans view the Black Lives Matter movement. Pew Research Center.

[50] Papacharissi, Z. and de Fatima Oliveira, M. 2012. Affective news and networked publics: The rhythms of news storytelling on\# Egypt. Journal of Communication. 62, 2 (2012), 266-282.

[51] Park, A. 2017. \#MeToo reaches 85 countries with 1.7M tweets.

[52] Partisanship and news behavior: 2017. https://www.americanpressinstitute.org/publications/reports/surveyresearch/partisanship-news-behavior/. Accessed: 2019-03-28.

[53] Poll: 57 percent have negative view of Black Lives Matter movement: 2017. https://thehill.com/homenews/campaign/344985-poll-57-percent-have-negative-view-of-black-lives-matter-movement. Accessed: 2019-03-29.

[54] Ramírez, G.B. Hashtivism as public discourse: Exploring online student activism in response to state violence and forced disappearances in Mexico. Research in Education.

[55] Rho, E.H.R., Mark, G. and Mazmanian, M. 2018. Fostering Civil Discourse Online: Linguistic Behavior in Comments of \#MeToo Articles Across Political Perspectives. Proceedings of the 21st ACM Conference on Computer Supported Cooperative Work \& Social Computing (New York, NY, USA, 2018), 147-175.

[56] Rodino-Colocino, M. 2018. Me too,\# MeToo: countering cruelty with empathy. Communication and Critical/Cultural Studies. 15, 1 (2018), 96-100.

[57] Rodino-Colocino, M. 2014. \#YesAllWomen: Intersectional Mobilization Against Sexual Assault is Radical (Again). Feminist Media Studies. 14, 6 (Nov. 2014), 1113-1115. DOI:https://doi.org/10.1080/14680777.2014.975475.

[58] Romero, D.M., Meeder, B. and Kleinberg, J. 2011. Differences in the Mechanics of Information Diffusion Across Topics: Idioms, Political Hashtags, and Complex Contagion on Twitter. Proceedings of the 20th International Conference on World Wide Web (New York, NY, USA, 2011), 695-704.

[59] Romero, D.M., Meeder, B. and Kleinberg, J. 2011. Differences in the mechanics of information diffusion across topics: idioms, political hashtags, and complex contagion on twitter. Proceedings of the 20th international conference on World wide web (2011), 695-704.

[60] Santiago, C. and Criss, D. 2017. An activist, a little girl and the heartbreaking origin of "Me too." CNN.

[61] Simpson, E. 2018. Integrated \& Alone: The Use of Hashtags in Twitter Social Activism. Companion of the 2018 ACM Conference on Computer Supported Cooperative Work and Social Computing - CSCW '18 (Jersey City, NJ, USA, 2018), 237-240.

[62] Small, T.A. 2011. What the Hashtag? Information, Communication \& Society. 14, 6 (Sep. 2011), 872-895. DOI:https://doi.org/10.1080/1369118X.2011.554572. 
[63] Starbird, K. and Palen, L. 2012. (How) Will the Revolution Be Retweeted?: Information Diffusion and the 2011 Egyptian Uprising. Proceedings of the ACM 2012 Conference on Computer Supported Cooperative Work (New York, NY, USA, 2012), 7-16.

[64] Stewart, L.G., Arif, A., Nied, A.C., Spiro, E.S. and Starbird, K. 2017. Drawing the Lines of Contention: Networked Frame Contests Within \#BlackLivesMatter Discourse. Proc. ACM Hum.-Comput. Interact. 1, CSCW (Dec. 2017), 96:196:23. DOI:https://doi.org/10.1145/3134920.

[65] Sunstein, C.R. 2018. \# Republic: Divided democracy in the age of social media. Princeton University Press.

[66] Taub, A. 2017. The Real Story About Fake News Is Partisanship. The New York Times.

[67] Taub, A. 2017. Why Americans Vote 'Against Their Interest': Partisanship. The New York Times.

[68] The backlash against Black Lives Matter is just more evidence of injustice: http://theconversation.com/the-backlashagainst-black-lives-matter-is-just-more-evidence-of-injustice-85587. Accessed: 2019-04-04

[69] Tilly, C. 1978. From Mobilization to Revolution. McGraw-Hill.

[70] Tolentino, J. 2018. The Rising Pressure of the \#MeToo Backlash. The New Yorker.

[71] Yang, G. 2016. Narrative Agency in Hashtag Activism: The Case of \#BlackLivesMatter. Media and Communication. (Jan. 2016), 13-17. DOI:https://doi.org/10.17645/mac.v4i4.692.

[72] Yang, L., Sun, T., Zhang, M. and Mei, Q. 2012. We Know What @You \#Tag: Does the Dual Role Affect Hashtag Adoption? Proceedings of the 21st International Conference on World Wide Web (New York, NY, USA, 2012), 261270.

[73] 2018. After a year of \#MeToo, American opinion has shifted against victims. The Economist.

[74] 2016. History of the hashtag \#BlackLivesMatter: Social activism on Twitter.

[75] 2015. Is politics on Twitter a man's world?

Received April 2019; revised June 2019; accepted August 2019. 